\title{
Portosystemic shunt via the superior mesenteric and right ovarian vein leading to small intestine bleeding in alcoholic liver cirrhosis
}

\author{
Sanjeev Vamadevan, Tobias Haltmeier, Yves Groebli
}

Department of Surgery, Hospital of Neuchâtel, Neuchâtel, Switzerland

\section{Correspondence to} Dr Sanjeev Vamadevan, vamadevan.sanjeev@gmail. com
To cite: Vamadevan $S$ Haltmeier T, Groebli Y. BMJ Case Rep Published online: [please include Day Month Year] doi:10.1136/bcr-2013008959

\section{DESCRIPTION}

A 48-year-old woman with a history of longstanding alcohol consumption, arterial hypertension and morbid obesity was admitted to our emergency department due to massive haematochezia and dyspnoea. She was drowsy, tachypneic $(28 \mathrm{breath} / \mathrm{min})$ and icteric on admission. Blood pressure was $70 / 30 \mathrm{~mm} \mathrm{Hg}$ and pulse rate $100 / \mathrm{min}$. Physical examination revealed a tender abdomen and fresh blood on the digital rectal examination. Laboratory findings were as follows: haemoglobin $8.5 \mathrm{~g} / \mathrm{dl}$; haematocrit $25 \%$; platelets $2.21 \times 10^{5} / \mathrm{mm}^{3}$; prothrombin time $47 \%$ (INR 1.46 ); urea nitrogen $59.1 \mathrm{mg} / \mathrm{dl}$; total bilirubin $4.1 \mathrm{mg} / \mathrm{dl}$; direct bilirubin $2.9 \mathrm{mg} / \mathrm{dl}$; aspartate aminotransferase/ alanine aminotransferase 152/62 IU/1; alkaline phosphatase $142 \mathrm{IU} / 1$ and $\gamma$-glutamyltransferase $226 \mathrm{IU} / \mathrm{l}$. Hepatitis B and C serology was negative. An alcoholic liver cirrhosis Child-Pugh class B with a score of 8 points was diagnosed.

Abdominal ultrasound showed a normal gallbladder with gallstones but without signs of cholecystitis. Intrahepatic bile ducts were not dilated; the extrahepatic bile ducts were not visualised, as the examination was difficult because of obesity. As there where no signs of portal hypertension, Doppler ultrasound was not performed. Upper gastrointestinal endoscopy was normal. Colonoscopy showed fresh blood that was leaking through the ileocecal valve. Visualisation of the ileum by colonoscopy was not achieved. No active bleeding was found in the colon. Selective arteriography was subsequently performed without visualisation of an active bleeding. An abdominal angio CT scan was performed which showed signs of portal hypertension with ascites and a portosystemic shunt via the superior mesenteric vein (SMV) and the right ovarian vein (ROV), as well as varices of the SMV (figures 1-3). The SMV varices were in close contact with the terminal ileum. A capsule endoscopy was not performed, based on the abovenamed CT findings.

Given the context of a cirrhotic coagulopathy and a portosystemic shunt in proximity to the terminal ileum, small bowel bleeding in this case was caused by perforated bleeding varices of the SMV. Despite the transfusion of 9 units of red blood cells, 13 units of fresh frozen plasma and $4 \mathrm{~g}$ of fibrinogen, respectively, there was ongoing intestinal bleeding. Transjugular intrahepatic portosystemic shunt (TIPS) was performed with a consecutive reduction of the portal pressure from 26 to $16 \mathrm{~mm} \mathrm{Hg}$.

After TIPS, no further intestinal bleeding was observed and haemoglobin remained stable.

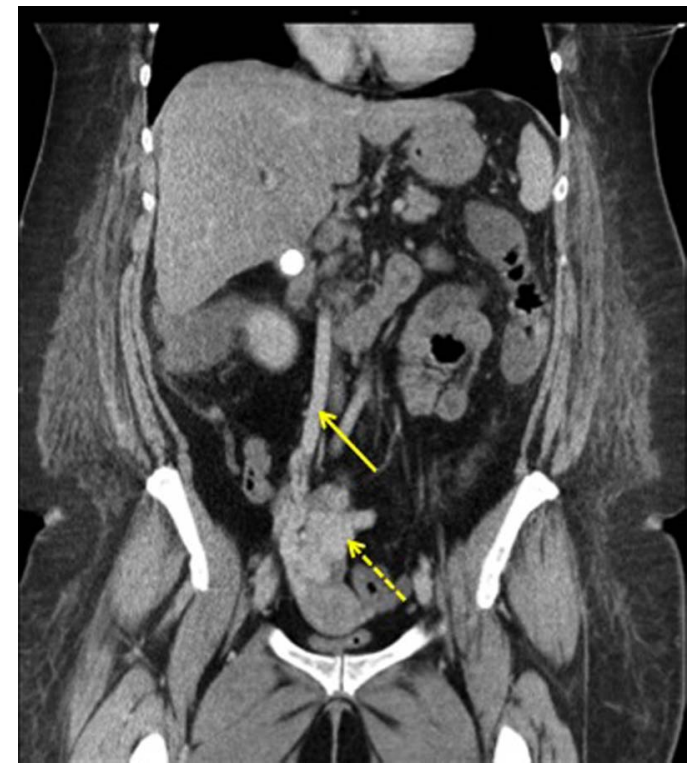

Figure 1 Abdominal CT scan - frontal view contrast-enhanced abdominal CT scan showing the portosystemic shunt via the right ovarian vein (ROV). Arrow, ROV; dashed arrow, shunt.

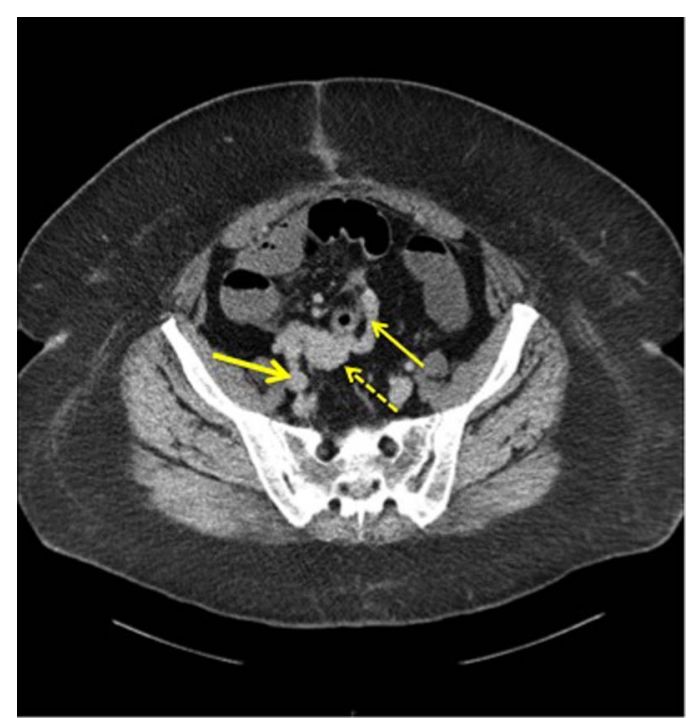

Figure 2 Abdominal CT scan-axial view contrast-enhanced abdominal CT scan showing the portosystemic shunt via the superior mesenteric vein (SMV) and right ovarian vein (ROV). Arrow, SMV; dashed arrow, shunt; bold arrow, ROV. 


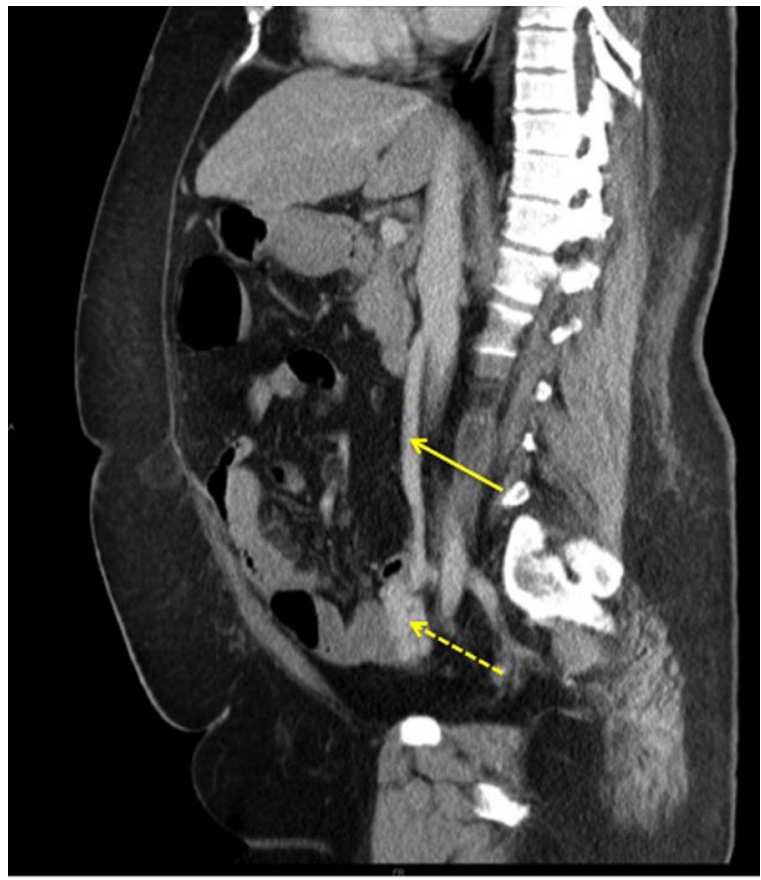

Figure 3 Abdominal CT scan-sagittal view contrast-enhanced abdominal CT scan showing the portosystemic shunt via the right ovarian vein (ROV). Arrow, ROV; dashed arrow, shunt.

Postinterventional course was uneventful and the patient could be discharged home 2 weeks later. Follow-up after 9 months revealed no recurrence of intestinal bleeding.

Bleeding from ectopic varices is rare in patients with portal hypertension ( $5 \%$ of all variceal bleeding). It is generally massive and life threatening. ${ }^{1}$
Evidence for the treatment of ectopic varices is poor, as treatment recommendations are limited to case reports. ${ }^{1}$ There are different therapeutic option in bleeding ectopic varices, such as balloon occluded retrograde transvenous obliteration, ${ }^{2}$ transcatheter embolisation or sclerotherapy, with or without portosystemic TIPS. ${ }^{3}$ Thus, a multidisciplinary approach (intensivists, gastroenterologist, interventional radiologist and surgeons) is needed to define the optimal treatment strategy for patients with ectopic varices.

\section{Learning points}

- Haemorrhage from ectopic varices should be considered in patients with portal hypertension and lower gastrointestinal bleeding.

- There is no diagnostic workup for bleeding ectopic varices established at present. Angio CT scan is feasible for the visualisation of ectopic varices.

\section{Competing interests None.}

\section{Patient consent Obtained.}

Provenance and peer review Not commissioned; externally peer reviewed.

\section{REFERENCES}

1 Akhter NM, Haskal ZJ. Diagnosis and management of ectopic varices. Gastrointest Interv 2012;1:3-10.

2 Sato T, Yamazaki K, Toyota J, et al. Akaike lleal varices treated with balloon-occluded retrograde transvenous obliteration. Gastroenterol Res 2009;2:122-5.

3 Lopez-Benitez R, Seidensticker P, Richter GM, et al. Massive untere gastrointestinale Blutung aus ilealen Varizen. Radiologe 2007;47:407-10.

Copyright 2013 BMJ Publishing Group. All rights reserved. For permission to reuse any of this content visit

http://group.bmj.com/group/rights-licensing/permissions.

BMJ Case Report Fellows may re-use this article for personal use and teaching without any further permission.

Become a Fellow of BMJ Case Reports today and you can:

- Submit as many cases as you like

- Enjoy fast sympathetic peer review and rapid publication of accepted articles

- Access all the published articles

- Re-use any of the published material for personal use and teaching without further permission

For information on Institutional Fellowships contact consortiasales@bmjgroup.com

Visit casereports.bmj.com for more articles like this and to become a Fellow 